\title{
\$sciendo
}

Ethics \& Bioethics (in Central Europe), 2018, 8 (1-2), 81-89

DOI:10.2478/ebce-2018-0003

\section{Truth and lies in journalism: A dispute concerning the accurate presentation of information}

\section{Dorota Probucka ${ }^{1}$}

\begin{abstract}
The aim of the article is to analyze the modern mass media, in which the line between truth and lies has been blurred, leading to a lack of responsibility for words and their cognitive value. In the first part of the article, the value of truth in journalism is explored and the professional ethos associated with it, known as being 'pro-truth'. In the second part, the negative effects of media lies and their various forms are described.
\end{abstract}

Keywords: mass media, manipulation, journalism, value, truth, falsehood, ethics

\section{Introduction}

One negative aspect of the present times is the collapse of professional media and responsible journalism. Even a dozen or so years ago, objectivity, thorough research and discussion of all aspects of the analyzed phenomenon were all seen as the basic principles of journalistic ethics. Currently, the main purpose of media messages is not reliable knowledge and deep reflection, but the triggering of preferred emotions in the target audience. This phenomenon has become so widespread that the editorial board of the Oxford Dictionary recognized the word "post-truth" as the most important word of 2016 and at the same time the most important event in the field of mass-media communication. "Post-truth" is a term describing a situation in which the main task of journalists and mass media is no longer to present objective facts, while strong emphasis is placed on evoking emotions. The most important feature of the "post-truth era" is that the stigmatization experienced by journalists who lie has disappeared. The liar has been freed from the burden of guilt and is no longer punished socially for his act through condemnation, rejection, refusal of co-existence and cooperation (Keyes, 2004, p. 149). Similarly, the categories of honesty and dishonesty have lost their own binary, zero-one nature. The old lies have been replaced by ambiguous, euphemistic statements. Thus, journalists no longer lie, they "depart from the truth", "exaggerate", "misspeak", "make erroneous judgments", "selectively present information". This phenomenon will have serious, negative consequences for social life and media credibility, because indifference towards the truth and lies will lead to the weakening of interpersonal bonds and mutual trust.

\section{The significance of truth in journalistic work}

Normative ethics stresses the importance of truth understood as a value that organizes interpersonal relationships and increases the level of social trust. The idea of truth is associated with the postulate of truthfulness, understood as the conscious expression of true statements, i.e. ones that are in line with reality. According to ethicists, respect for the truth and practicing truthfulness should be the primary goal of mass media employees, which will ensure that they are reliable, respectable and trustworthy people. A journalist who does not strive for the truth accepts a false picture of the reality surrounding him and has less orientation in the world as it is. He lives in illusion and feeds illusions to his audience. In this case, being in truth would be associated with a cognitive honesty towards oneself and others.

\footnotetext{
${ }^{1}$ Cracow Pedagogical University (Poland); email: dorotaprobucka@op.pl
} 
Unfortunately, only a small percentage of people have this ability fully developed, which would indicate a high level of mental and moral maturity.

First and foremost, each mass media employee should know what the truth is, how it is defined, and what so-called being in truth means. Knowledge in this area, and volitional orientation aimed at the realization of this value would determine the professionalism and the moral value of a journalist. Let's pay special attention to the postulate of being in truth. This means honesty towards oneself and other people associated with striving to ensure that the media message is free of adulterations, self or group interests, prejudices, thought stereotypes, fears and hatred. Let us recall that in ancient Greek ethics, truth was defined by the word aletheia, meaning unconcealment, disclosure, transparency. Such an understanding of truth has not become obsolete and is still valid today. Therefore, the goal of the mass media should be to disclose, reveal that which has been deliberately concealed, or not made available to the public. Moreover, in this approach, truth is not only the opposite of a lie, but also of individual and collective oblivion. After all, in Greek mythology, the word Lete originally meant the name as the river, after crossing which the dead lost their memory. Thus, the journalistic postulate of being in truth should also be equivalent with the nurturing of collective, historical memory. Let us emphasize that if a journalist should be in truth, then he must be a guardian and a spokesperson for social memory. However, if he should remember, then that should only be in truth. This would mean not ignoring, not downplaying, not deforming, not erasing certain facts and the suffering associated with them from the collective consciousness. This type of journalistic being in truth, understood as nurturing social memory, would also be an act of moral justice towards the victims of evil. Legal justice is not always possible and in such cases respect for the victims of other people's wickedness can be shown symbolically by the mass media in the form of truth understood as disclosure. Such a media message would constitute a symbolic restoration of existence to those whose suffering and death was thrown into social non-existence. Thus, the postulate of moral justice would mean that the mass media will enable people to speak about their own tragedy. If the mass media give up on such a mission, that is, deny the truth, this will create a cognitive dissonance and moral disintegration, in which people and entire societies cannot function for a long time. That is because only truth has the power to integrate and to deliver from evil. - Why? because thanks to it we are able to avoid this evil in the future. After all, the awareness of wicked conduct, present in a given society, can persuade people to engage in collective reflection and cause a change in behavior in the future. Therefore, the memory of what was done in the past is a prerequisite for abandoning similar behaviors in the future. Let us emphasize that mass amnesia maintained by the mass media prevents society from learning from its own mistakes and makes people morally blind. If, therefore, societies manipulated by the mass media forget about their own faults or are not aware of them, they will start repeating similar mistakes. Thus, the restoration of memory through mass media is at the same time a restoration of a sense of social responsibility. From a psychological point of view, the measure of individual and collective maturity is the courage to admit guilt and the will to correct the evil that was done by turning towards the good. Suppressing certain facts from the collective consciousness would indicate individual or social infantilism. Nurturing such infantilism by the mass media would block the developmental capabilities of both individuals and entire societies. This type of situation would also occur in the case of cultivation of a deformed and exaggerated memory by the mass media. In turn, such activities may build a victim mentality in individuals and societies, which makes it impossible to build partner relations with other societies, and may reduce the sense of collective and individual value (Williams, 2002, p. 58).

We should pay attention to one more feature of being in truth, which should accompany the activities of mass media employees. It is the postulate of the coherence of words, declarations and deeds. This means a moral transparency understood as a way of being in 
which the deeds are a confirmation of the declarations previously made. Journalistic unconcealedness is the unity of words and deeds that would not only demonstrate lofty morals, but would also indicate a progressing process of humanization. That is because the orientation on truth really renders our lives more human. Meanwhile, turning away from the truth means professional hypocrisy understood as a way of life. Let us remember that a hypocrite is not only someone who is lying. A hypocrite is someone who has lost the ability to distinguish between lies and truth. Hypocrisy could be treated as a special case of individual or collective illness. Media hypocrisy would destroy the axiological dimension of culture, questioning the meaning of rules and values, and would lead to a moral and cognitive dissonance in which people cannot function for a long time. In order to avoid this, journalists and other mass media workers should be taught how to work on their own mind, in order to develop a level of thinking that was referred to in ancient ethics as orthos logos, and in medieval ethics as bona mens. The idea of orthos logos should guide the employees of mass media institutions. This is the development of an honest, righteous mind, the power of judgment, thanks to which a man utters not only logically correct conclusions, but above all serves the truth. It is a mind that cannot be instrumentalized, cannot be intimidated, or turned into a sycophant. A journalist who has developed a "good mind" does not want to manipulate others and does not agree to manipulation, he does not agree to the realization of other people's interests at the price of renouncing the truth.

\section{Lies in journalism}

The definition of a lie cannot be unambiguously established, because a lie can be defined in many ways, with emphasis placed on its various aspects. We can focus on the perpetrator who lies, or on the person who is lied to, we can analyze the lie itself as an activity, or take into account the relationship of the lie with the law and morality. In the case of mass media communication, lying is an act that denies the human right to truth. We should remember, however, that sending false information is not yet a lie, which is primarily based on a negative intention. A media lie is the intentional misleading of the audience, it is a false message deliberately sent to the media space. The journalistic manifestation of a lie can be a spoken or a written word or image containing a deformed message. Let us distinguish the six ways of lying to people. The first group would be associated with the media tendency to omit certain facts, information and messages. In this case, lying means concealment. The second group consists of: duplicity, hypocrisy, perversity, obliqueness of the employees of mass media institutions. The next group is lies which deny not only the truth, but also the dignity of another human being. These include: slander understood as the false attribution to some person of deeds or traits that offend him, derision combining mockery, laughter and distorted truth, and slander - a combination of calumnies and lies. The fourth group includes lies understood as a media ruse consisting of boasting, presented as a harmless form of jokes, and a ruse, the aim of which is to ridicule the opponent. Deception is the determinant of the fifth group, and involves the creation of media illusions, deceiving the audience with the desired vision of the world that is objectively unrealistic. The sixth group includes all the media lies that take the form of manipulation. All lies belonging to this group are embedded in the social context. A typical example is the media propagation of gossip, understood as unverified information, which - despite everything - influence the opinions, attitudes and emotions of the audience. Generally speaking, such lies are based on the biased selection and ordering of events contained in information, exaggeration or minimization and the blurring of the lines between objective description and subjective judgment. In addition, this practice would consist of deliberate omission or emphasizing of certain arguments, the adoption of one-sided assessment criteria, or unclear judgments and concepts (Campbell, 2001, p. 89). 
Another very interesting interpretation of media lies concerns two ways in which they manifest themselves. The first of them is a lie understood as an excess of truthfulness. The second of them is a lie synonymous with incomplete, limited truthfulness. In the first case, media overzealousness in revealing the truth consists of a lack of respect for the dignity and intimacy of the people to whom this truth relates. This is one of the major problems in the sphere of mass media messages, which can lead to the destruction of social life. In this case, the lie does not involve false messages, but instead consists of not respecting the moral norm that calls for respect for the dignity of another human being. A factor which would in this case limit the invasive, nosy nature of the media would be a law that prohibits the publication of private data without the consent of the persons concerned, provided that these people are not engaged in public activities. This nosiness based on the practice of peeping and revealing, does not apply to all spheres of private life, but to those that are most disturbing, such as sexual relations, marriage and cheating.

Let's now reflect on lies understood as the insufficiency of truthfulness. In this case, the researchers distinguish several methods in which mass media lie to their audiences through the transmission of information inadequate to reality. The first one consists in choosing such values and content that attract the attention of the audience, and in addition, this selection is not intuitive but is the result of painstaking, psychological research. Unfortunately, the most effective factors that intensify media activity and thus multiply the financial profits of media companies are: sex, violence, situations of conflict and competition. Let us note that the amount of aggression and brutality shown, for example, on the television, far exceeds their presence in the real world. The saturation of media messages with aggression causes the recipients to become indifferent and see such phenomena as normal, usual and common. Indifference towards rape, crime, financial fraud and corruption is also becoming increasingly common. This phenomenon would be one of the manifestations of moral depravity and the disappearance of critical thinking, promoted especially by television. The second method consists in combining the transmission of information with a dimension of entertainment and fun. Such a message deforms and reduces the sense of the meaning of life, for which entertainment and fun become the guiding values. This type of lie leads to the infantilization of life, by impoverishing the axiological dimension of human existence. Another method of lying understood as the transmission of limited truth is the selection of information. Its application does not necessarily have to be associated with official censorship and may have more prosaic manifestations, associated not so much with ideological issues, but with commercial and mercantile considerations. In this case, the concealment of truth would include, for example, the authors of advertisements failing to provide full information about the product being sold, i.e. hiding its flaws. The fourth method of media lying would involve the use of the persuasive function of language and assigning other meanings to names. In this way concepts with a traditional, negative connotation gain a new, positive meaning and therefore change the response of the audience to a specific message. Another method would be based on misleading the audience by manipulating the results of polls. Appealing to the results of polls is intended to authenticate the content of the media message, unfortunately the polls themselves do not have to be carried out in a methodologically correct manner, but the audience is not informed about this. The sixth method of media lying is the impact of the message on the subconscious of the audience. In this case, it is not the word that has the greatest impact, but the image, because the human brain gets $60-80 \%$ of information through visual perception. Images have the greatest initial, persuasive strength, because the human brain accepts the conceptual and verbal content as secondary. It could be said that the recipient of mass media messages presented by means of images is completely defenseless against such messages and easily succumbs to their influence. The content contained in the images is not accepted in a discursive or fully conscious manner. These are messages that 
activate the subconscious, a typical example of which could be visual advertisements. In general, its effectiveness in influencing the viewers is based on the fact that it is very difficult for people to reject the original message flowing from the sensual impulses, which is imprinting content in our deepest, unconscious sphere. The classic example is so-called subliminal advertising, which involves sending visual or auditory stimuli that are too brief to be consciously registered. It is important to remember that this problem became very controversial after the experiment conducted in 1957 by James Vacary in the United States. He replaced some film frames in movies presented in a drive-in cinema with the words "drink cola" and "eat popcorn", attempting to induce the audience to buy these products (Gabler, 1998, p. 78).

\section{Manipulation of information as a special form of journalistic lies}

The 20th century has been referred to as the century of manipulation. Unfortunately, mass media were one of the main tools that ensured the mass character of this phenomenon. Manipulation is a phenomenon that occurs between the sender and the recipient, when the sender wants to influence the recipient, but the mechanism of that influence is concealed from the recipient. Thus, the sender wants to influence the recipient using secretive, hidden methods. This is precisely the deceptive nature of media manipulation, which not only applies to the objectives, but above all, to the means being used. Manipulation is generating false beliefs, which are to spread across groups or entire societies, by means of concealed techniques. The purpose of this method is to impose upon people a specific intellectual orientation, ideological formation, mold, and training. The essence of manipulation is the reification, objectification of man, exploitation of man as a means for the implementation of particular goals. It is the domination and subordination of man, turning man into passive tools. Thus, the act of manipulation is a reductionist and flattening act, which impoverishes human nature and negates its personal dimension. Media manipulation is targeted against the four personal values of human beings. The first of these is decision-making autonomy, which is violated when a person is treated instrumentally. The second value is the free development of every person, which can be distorted through media influence. In this case, a particularly negative impact is observed in the manipulative impact of advertising on the youngest generation. The third value, especially destroyed by manipulative methods, is human subjectivity and causative independence, which means that each of us may not want what others want. In the case of manipulation, our will becomes compatible with someone else's wishes. The fourth endangered value is rationality, because manipulation is a specific and irrational form of acting under someone's influence. The manipulator takes away or diminishes someone's ability to think rationally. Let us emphasize that manipulation always hurts people, because it distorts the stability of personality and psychological balance, introduces a sense of dependence and danger, increases fear, tension and stress. This particular way of exerting influence on others is based on disregarding, deprecating and humiliating.

The use of media to control people on a mass scale is present in both totalitarian and democratic regimes, however, success in this regard is not determined by a one-off message, but by long-term and multilateral manipulation. In addition, this success is also associated with bringing people to such a psychophysical condition that makes them vulnerable to external influence. This situation is referred to as social alienation (Marcuse, 1991, p. 127). It is important to remember that by becoming a cog in an automatic production process, man loses his humanity, intellectual independence and creative desire and power. According to Herbert Marcuse, an alienated person limits his activity to the long working day and loses his individuality, subordinated to production. If $1 / 3$ of his day is focused on one, monotonous activity, he has no strength and he has no conditions to think independently and creatively. As 
a result, millions of people are starting to form a homogeneous mass that is easy to manipulate. We should also emphasize the presence of a psychosocial phenomenon in which most people are succumbing to manipulation because they want to. In every society there is an element of cultural constant concerning the common attitude of silent consent to manipulation and its social justification in exchange for exemption from responsibility for oneself and others.

In totalitarian systems, media manipulation serves propaganda purposes, falsification of history, and the glorification of the existing political system. When a certain group obtains and strengthens its political power, a process is launched in which media are used to justify this power and to build satisfaction with the new order. Economic, scientific and technical successes are promoted in the media, while events that could harm the rulers are covered up. The language of media propaganda manipulates various slogans for so long, that they start to sound natural and consistent in the minds of the audience. The semantics and syntax of the language of propaganda is deliberately processed and takes on the form of newspeak, the goal of which is the elimination of concepts that are detrimental to the currently prevailing ideology (Ellul, 1973, p. 85). Within the framework of newspeak it is impossible to formulate opinions critical of the prevailing regime. If media propaganda does not manage to keep the minds of the citizens in check, then the state uses terror, or the threat of terror. Terror itself is not manipulation, as it is open. In this case, covert exertion of influence is an additional factor, which consists of creating a general atmosphere of constant threat in society. Sociological research indicates that in the face of threats, especially those posed by an external enemy, society becomes more consolidated and more favorable towards the decisions of its own government. That is why many totalitarian regimes create artificial enemies. This type of unethical modeling of social awareness results in a lack of sense of security, a decrease in mutual trust and an increase in forced loyalty towards the state apparatus.

Media manipulation of society is not only the domain of totalitarian regimes. Attempts to secretly influence public opinion are not uncommon in democratic systems based on free elections. Unfortunately, during the elections, public opinion can be manipulated by the media in many ways. One of them is falsified results of polls presented in the mass media right before the elections. Their goal is to convince the voters that the candidate who is leading in the polls has obtained social proof and is the best candidate. The second manipulative method of influencing voters, often employed by the media, is generating positive associations with the person presented. An example of this is the media presentation of politicians holding children in their hands. This trick is supposed to build sympathy among the audience by associating the politician with the attitude of a caring father, a good defender of the nation. Such a situation took place during the reign of Joseph Stalin and since then leaders have often used this method to build sympathy among the masses. Let us recall that Adolf Hitler and Benito Mussolini did the same thing. This example can be seen as one of the varieties of manipulation understood as pretending to be good. In general, the goal of political media manipulation is to create so-called false consciousness that paralyzes man's ability to be critical, to treat reality objectively and to distance himself from it. His consciousness becomes limited, and his image of the world becomes narrowed and deformed (Bernaus, 2004, p. 52). Let's emphasize that manipulation seeks to exclude the recipient's critical consciousness, so that the full picture of the given matter is hidden from him. The sender deliberately conceals selected aspects of an honest picture of reality, so that it appears unclear and ambiguous.

\section{Lies as journalistic demagoguery}

Journalistic demagoguery is a form of exerting influence on the audience through speech, prompting the audience to make some kind of choice based on the presentation of one-sided and emotional arguments. This type of demagoguery, above all, disrupts the thinking of the 
recipients of the linguistic message, especially in its cognitive-axiological aspect. It strikes at the feelings and attitudes that accompany this thinking process. Let us recall that thinking is guided by three elements: attention combined with reflection, memory and concepts, and the motivational system (Chudy, 2007, p. 48). This type of manipulation involves interfering with all three dimensions of human thinking and thus interfering with the perception of the world and other people. The goal of media demagoguery is to limit the reflection of the audience and to generate so-called unreflective behavior, which indicates a minimum of cognitive effort (Chudy, 2007, p. 48). Thus, a demagogic message is easily accepted, because it doesn't mobilize the audience to make the effort of fully understanding the information. Let us therefore recall a few selected, basic eristic methods that are still used today in communication in general, and in media communication in particular, and let us compare communication to a game in which participants use different tricks on each other in order to defeat the opponent (Schopenhauer, 2004, p. 10). The first trick is to expand, and exaggerate information presented by someone else. This method consists in extrapolating a given claim beyond the limits provided by the sender of the message. The person conducting the manipulation generalizes the statement of the opponent as much as possible, but stops one step before entering into the territory of absurd. At the same time, he presents his own position as narrowly and precisely as possible. Another eristic method, which is, incidentally, frequently used in politics and advertising, is the use of ambiguous words. This method is used in order to escape responsibility for a message presented in the media. If, for example, a politician fails to fulfill his promises or the product sold does not meet the advertising slogans, then the author of the message claims that he meant something different than what the recipient thought. Another method is to emphasize these features of a described phenomenon, which are especially important for the sender of the message. Thus, when a media manipulator proposes some changes, for example, in the organization of social life, he defines them as progressive, intended to combat stagnation and parochialism. If, however, the changes are not carried out in accordance with his intentions, he presents them as a pursuit of fleeting fashion trends, and then presents himself as a defender of tradition and the old order. This method is particularly demagogic in nature, and requires knowledge of media language and the human psyche. Language has the power to control human minds. Appropriate words not only betray the sender's attitude towards a given problem. Well-chosen words also send specific emotional content and hidden meanings into the recipient's mind. If a word used in a media message is new to the recipient and sounds unfriendly, then it will probably trigger a negative attitude in his mind. Based on this principle, for example, attorneys defending individuals accused of battery do not refer to their clients as "brutal, depraved criminals", but describe them as "lost individuals who unconsciously act out in reaction to their difficult childhood". Similarly, politically condemned armed groups are referred to as: "terrorists" or "bandits". Meanwhile, these groups do not refer to themselves in this way and use terms with a completely different meaning, such as: "insurgents", "patriots", "defenders", "partisans". The listener has quite different emotional reactions to the words "terrorist" and "martyr to a cause", even if it is known that they refer to the same person. Another eristic trick, often used by contemporary media, consists in appealing to an authority that supports the presented opinion. The mechanism of submission to specialists is deeply ingrained in human beings. People who are not familiar with a given subject have respect for all authorities and often accept their claims without any reflection. This phenomenon provides an effective method of manipulation, and in many cases it is magnified, if the authorities are false or if the statements of actual specialists are quoted in a selective and biased manner. 


\section{Lies as media psychological manipulation}

This kind of manipulation is more complicated than eristic tricks, and, interestingly, it is used instinctively in many cases, and also does not require greater familiarity with logic and language theory. The masters of media psycho-manipulation interfere with the will of the audience, striving to make them want what the manipulator wants. Eristic methods ensure victory in a media discussion, but they do not have to convince the adversary. Conversely, he is often convinced that he is right, although he was not able to defend his own position. On the other hand, the purpose of psychological manipulation is to influence the human psyche and the volitional sphere in such a sophisticated manner that the recipient of the message will be convinced that he made the decision on his own and in accordance with his own reasoning. One of the basic mechanisms on which media psycho-manipulation is based is the automation of human behavior. In the modern world, the pace of civilizational development is so fast that people are not able to follow all the changes that are taking place. The human brain is forced to select the information that reaches it, and only register some of it. After some time, the reaction to the incoming stimuli becomes automated (Cialdini, 2001, p. 53). The most popular example of this mechanism is the presence of red in the animal world. Red in reptiles or amphibians indicates that they are venomous, which should deter potential aggressors. These types of responses observed in animals are conditioned biologically, while in the case of humans they are learned and they are social in nature. Unconscious reactions to a specific stimulus are a component of the so-called automated thinking, which is exploited by media manipulators. This technique uses a situation in which the manipulated persons do not have the time to reflect on their reactions and passively record the information that is reaching them, using their existing cognitive scripts in their interpretation. In this case, one of the techniques is the repetition of certain content in the media. After a certain number of repetitions, the potential doubts of the recipient disappear and the statement is accepted completely and without reservations (Cialdini, 2001, p. 43).

Another manipulative mechanism is referring to social proof, which is frequently used in advertising broadcast in mass media. In an attempt to convince the audience to its content, the sender of a given message presents the largest possible group of people who agree with that message. Instead of focusing on the advantages of the offered product, many advertisements convince the audience that, for example, their product is the best-selling car of the year, or the most-frequently-selected pension fund. Politicians in their advertising campaigns also claim that they have the support of the majority of society. This method is well reflected by the words of Cavett Robert, a sales consultant quoted, by Robert Cialdini: "Because 95\% of people are imitators, and only 5\% are initiators, people are more convinced by the behavior of others than by any proof of product quality" (Cialdini, 2001, p. 62). In this case, the media exploit, on the one hand, the so-called group pressure and, on the other hand, the need for belonging and for social approval. This technique involves emphasizing the role of public opinion, as well as the image of the individual in the society, and exploits the automatisms based on an unconscious reaction to social assessments. Let us emphasize that socially strengthened automatisms and stereotypes enforce mechanical behaviors in the society. A person subjected to them ceases to be an autonomous, independently thinking individual, and becomes a member of the herd. The media very often use social stereotypes as simplified ideas, that contribute to the presentation of phenomena in a certain way and thus to the exertion of influence. Stereotypes always have a supra-individual connotation. Different behaviors are considered to be reprehensible and punishable by exclusion, hence disregard for social proof is perceived by the individual as a transgression.

Let's analyze one more type of media psycho-manipulation, i.e. gossip. The gossip genres in mass media are popular biographical books and memoirs, journals, social sections, interviews, "social corners" in magazines, the so-called gossip press (Thiele-Dohrman, 1975, 
p. 116). Journalistic gossip most frequently has a negative connotation and grows out of envy, suppressed aggression and frustration. It is an informational message, which is irrational and flows from emotional sources. So-called controlled gossip, which is a manipulation tool, is particularly dangerous in the context of social life. These are information, images and descriptions of events deliberately fabricated in the appropriate institutions. They are meant to induce public annoyance, and generate a state of uncertainty and lack of trust (Chudy, 2007, p. 100). Media gossip is revealed especially in situations of shortage of widely available information, and in conditions of political or moral tensions in society.

\section{Summary}

The new mass media, in which the line between truth and falsehood was blurred, have, to a large extent, shaped the life attitudes of modern man, determined through four metaphors: the tourist, the stroller, the vagabond and the player (Bauman, 1993, pp. 235-243). The value of truth is not crucial in any of these attitudes. For the "tourist", the basic feature of his relationship with other people is temporariness, and his main life goal is seeking intense, pleasurable experiences. The "stroller" does not establish deeper contacts with people and limits his life to episodic meetings. His relationships with people have no history and they will have no future due to their randomness. His life is characterized by superficiality and episodicity. In turn, the "vagabond" symbolizes freedom, which is not guided by any positive values. Variability, pursuit of constant change, becomes more important than finding a lasting goal in life. Meanwhile, the metaphor of the "player" symbolizes the attitude of a man for whom uncertainty and risk are the immanent features of life. This metaphor means a lack of an existential support point, lack of permanent axiological foundations and unchanging principles. Thus, the excess of the enormous amount of information sent by the mass media, deprived of order due to the lack of an objective hierarchy of values, leads to the disappearance of identity, the disappearance of purpose and sense of life in man. Human existence starts resembling a journey without direction.

\section{References}

BAUMAN, Z. (1993): Postmodern Ethics. Oxford: Basil Blackwell.

BERNAUS, E. L. \& MILlER M. C. (2004): Propaganda. New York: IG Publishing. CAMPBELL, J. (2001): The Liar's Tale: A History of False Hood. New York: Norton.

CIALDINI, R. (2001): Influence: The Psychology of Persuasion. Boston: Allyn \& Bacon.

CHUDY, W. (2007): Klamstwo jako metoda [Lie as a method]. Warszawa: Oficyna Naukowa.

ELLUL, J. (1973): Propaganda: The Formation of Men's Attitudes. New York: Vintage Books.

GABLER, N. (1998): Life and Movie: How Entertainment Conquered Reality. New York: Knopf.

KEYES, R. (2004): The Post-Truth Era: Dishonesty and Deception in Contemporary Life. New York: Museum Martin Press.

MARCUSE, H. (1991): One-Dimensional Men: Studies in Ideology of Advanced Industrial Society. London: Routledge.

MROZOWSKI, M. (2007): Media masowe [Mass media]. Tarnów: ASPRA-JR.

SCHOPENHAUER, A. (2004): The Art of Always Being Right. Thirty Eight Ways to Win When You are Defeated. New York: Gibson Square Books.

SULLIVAN, E. (2001): The Concise Book of Lying. New York: Farrar, Straus and Giroux. THIELE-DOHRMANN, K. (1975): Zur Psychologie des Klatsches. Hamburg: Classen Verlag.

WILLIAMS, B. (2002): Truth and Truthfulness. Princeton: Princeton University Press. 